\title{
NUCLEIC ACID HOMOLOGIES BETWEEN THE \\ A AND T TYPES OF PASTEURELLA HAEMOLYTICA
}

\author{
E. L. Biberstein and Carolyn K. Francis \\ Department of Veterinary Microbiology, University of California, \\ Davis, California, USA
}

THE A and T types of Pasteurella haemolytica were first described and characterised by G. R. Smith $(1959,1961)$. At about the same time Biberstein, Gills and Knight (1960) suggested a grouping of their strains into two divisions on serological, biochemical and ecological grounds. These two divisions turned out to be roughly analogous to Smith's A and T types. Among the differential characteristics of the two biotypes the following appear to be the most helpful.

Type A

(1) Acid produced from arabinose (10 days).

(2) No acid produced from trehalose (10 days).

(3) Highly susceptible to penicillin in vitro.

(4) Cultures die off rapidly.

(5) Small grey colonies.

(6) Capsular serotypes $1,2,5,6,7,8,9,11$ and 12.

(7) Major somatic serotypes A and B.

(8) Predominant in pneumonia of cattle and sheep, and septicaemia of newborn lambs.

(9) Common in nasopharynx of normal cattle and sheep.
Type $T$

(1) No acid produced from arabinose (10 days).

(2) Acid produced from trehalose (10 days).

(3) Relatively resistant to penicillin in vitro.

(4) Cultures survive longer.

(5) Larger colonies with tan-coloured centres.

(6) Capsular types 3, 4 and 10.

(7) Major somatic serotypes C and D.

(8) Predominant in septicaemia of lambs $3 \mathrm{mth}$ of age or older.

(9) Uncommon in nasopharynx of normal cattle and sheep.

Although these differences are largely of a quantitative rather than a qualitative nature, in the aggregate they amount to more than have been considered to justify the separation of species in other taxa. In fact, Smith and Thal (1965) concluded from a taxonomic study in which they utilised numerical techniques and measured more than 50 characters, that $\mathrm{A}$ and $\mathrm{T}$ types differed markedly from each other and that further studies might well furnish grounds for regarding the $\mathrm{A}$ and $\mathrm{T}$ types as separate species.

In recent years much use has been made of the method of producing hybrids from nucleic acids extracted from different bacteria as a means of clarifying the taxonomic position of the bacteria. This appeared to be a promising method for determining the degree of genetic relationship between strains of the A and T biotypes of $P$. haemolytica.

Received 9 Feb. 1968; accepted 26 Feb. 1968.

J. MED. MICROBIOL.-VOL. 1 (1968) 


\section{MATERIALS AND METHODS}

Strains. Two type-A and one type-T strains of Pasteurella haemolytica and a single strain of P. multocida were examined. One of the biotype-A strains, no. 636, had been obtained from a case of bovine pneumonia and was identified as capsular type 1, somatic type A. The other strain of biotype A, no. H58, was capsular type 2, somatic type B; it had been recovered from a case of ovine pneumonia. The biotype-T strain, no. 1374, originated from a typical outbreak of septicaemic pasteurellosis in a flock of feeder lambs. Its capsular serotype was 4 and its somatic type was D. The strain of $P$. multocida was of capsular type A (Carter, 1952) and had been isolated from a turkey that died in an attack of acute fowl cholera.

Preparation of DNA. The source of deoxyribonucleic acid was a culture of bacteria grown to late exponential phase in brain heart infusion broth (Difco) on a shaker (New Brunswick) at $37^{\circ} \mathrm{C}$. DNA was extracted and purified by the phenol method of Kaiser and Hogness (1960), which employs repeated phenol and ethanol precipitations followed by treatment with ribonuclease (RNase). The RNase was removed by exposing the solution to pronase for $2 \mathrm{hr}$ as suggested by Gillespie and Spiegelman (1965). Pronase was removed by further precipitations with phenol followed by precipitations with ethanol. When the DNA was of sufficient purity, as determined spectrophotometrically, it was denatured by heating the solution in a waterbath at $100^{\circ} \mathrm{C}$ for $15 \mathrm{~min}$. This treatment was followed by chilling in an ice-bath to prevent renaturation. The degree of denaturation was checked by following the increase of optical density in a spectrophotometer (DB, Beckman). The minimum acceptable degree of denaturation was that corresponding to an increase of about 25 per cent. in the solution's optical density at $260 \mathrm{~m} \mu$. The denatured DNA was placed on Schleicher and Schuell cellulose nitrate filters (type B6) according to the method of Gillespie and Spiegelman. Each filter was exposed to $100 \mu \mathrm{g}$ DNA. Actual amounts bound to the membrane were calculated on the basis of optical density measurements of the filtrate at $260 \mathrm{~m} \mu$. They ranged from 65 to $82 \mu \mathrm{g}$. Filter membranes were dried for $2 \mathrm{hr}$ at room temperature and then for an additional $2 \mathrm{hr}$ in a drying oven at $80^{\circ} \mathrm{C}$. Storage was at room temperature under vacuum in a desiccator jar.

Preparation of RNA. For the production of labelled messenger ribonucleic acid (mRNA) bacteria were grown in brain heart infusion broth on a shaker to an optical density (OD640) value of $0 \cdot 3$, harvested at room temperature under sterile precautions and washed once in tissue culture medium no. 199 (without phenol red, Difco). They were resuspended in a 25 per cent. solution of medium no. 199 in 0.85 per cent. $\mathrm{NaCl}$ at $37^{\circ} \mathrm{C}$. The details of the labelling procedure were as described by Doi and Igarashi (1964): $20 \mu \mathrm{Ci}{ }^{3} \mathrm{H}$-uridine (New England Nuclear Corp.) were added to each $1 \mathrm{ml}$ and the mixture was incubated for $3 \mathrm{~min}$. at $37^{\circ} \mathrm{C}$ for pulse labelling. The reaction was stopped by pouring the mixture over an approximately equal volume of frozen Tris-magnesium chloride buffer ( $0.1 \mathrm{M}$-Tris and $0.005 \mathrm{M}-\mathrm{MgCl}_{2} ; p \mathrm{H} \mathrm{7.3)}$. The bacteria were sedimented in a refrigerated centrifuge at $4^{\circ} \mathrm{C}$, washed once in a solution of $0.15 \mathrm{M} \mathrm{NaCl}$ and $0.1 \mathrm{M}$ disodium ethylenediaminetetraacetate (saline-EDTA). The extraction and purification of the RNA were then completed by the method of Gierer and Schramm (1956).

Annealing process. The hybridisation procedure and the preparation of the filter membranes for radioactive counting were done according to the recommendations of Gillespie and Spiegelman. The amount of RNA used for hybridisation was equivalent to $2 \times 10^{5}$ counts per min. After being washed, treated with RNase, rewashed, and dried, the filters containing the hybrids were placed in scintillation fluid and counted in a scintillation counter (Nuclear-Chicago).

Extensive preliminary trials led to the adoption of a pattern of experiment in which one lot of DNA was tested against a battery of labelled RNAs of different origins. We found that this procedure gave comparable and reasonably consistent values, whereas the reverse procedure, i.e., the testing of one lot of RNA against different batches of DNA, gave erratic results that were difficult to interpret. The most disturbing of the results were grossly paradoxical reactions, in which the degree of hybridisation with heterologous strains was 
several times that in the homologous system. These peculiar findings were ascribed to differences in the quality of the different lots of DNA. Similar differences were not observed among the RNA preparations.

All hybridisation attempts were performed at least in duplicate.

\section{RESULTS}

The percentage homologies obtained between the nucleic acids of cultures of Pasteurella haemolytica and P. multocida are given in the table. The values for each cross are based on the averages of at least two hybridisation experiments. Background counts, which were obtained by processing filter membranes devoid of DNA through the hybridisation steps and reading them in the scintillation counter, have been deducted. Since the DNA content of different membranes varied, all counts have been corrected to an equivalent of $100 \mu \mathrm{g}$ before calculation of the percentage homologies.

TABLE

Degree of genetic relationship between strains 636 and $H 58$ of Pasteurella haemolytica type A, strain 1374 of P. haemolytica type T and strain JB30 of P. multocida, as indicated by the extent of hybrid formation between $D N A$ and ${ }^{3} \mathrm{H}$-labelled $m R N A$ from different pairs of strains

\begin{tabular}{|c|c|c|c|c|}
\hline \multirow{2}{*}{ Strain from which DNA was obtained } & \multicolumn{4}{|c|}{$\begin{array}{l}\text { Percentage homology indicated by the extent of } \\
\text { hybrid formation * when DNA was tested with } \\
\text { mRNA from strain }\end{array}$} \\
\hline & 636 & H58 & 1374 & JB30 \\
\hline $\begin{array}{l}\text { P. haemolytica type A, strain } 636 \\
P . \text { haemolytica type A, strain H58 } \\
P . \text { haemolytica type T, strain } 1374 \text {. } \\
P . \text { multocida strain JB30 }\end{array}$ & $\begin{array}{r}100 \\
102 \\
24 \\
13\end{array}$ & $\begin{array}{r}83 \\
100 \\
8 \\
0\end{array}$ & $\begin{array}{r}30 \\
50 \\
100 \\
18\end{array}$ & $\begin{array}{l}\ldots \dagger \\
\ldots \\
\ldots \\
100\end{array}$ \\
\hline
\end{tabular}

* Each result is the average for at least two experiments.

$\dagger$ Not tested.

The table clearly shows three homology patterns: the DNA preparations from strain 1374 of $P$. haemolytica type T and strain JB30 of $P$. multocida did not form hybrids to any significant degree with the RNA from any but the homologous strain; the DNAs from strains 636 and H58 of $P$. haemolytica type A reacted strongly with the RNA from either of these strains, but only weakly with that from the type-T strain (no. 1374).

\section{Discussion}

The patterns of hybridisation observed in our experiments suggest that the genetic relationships in this group of pasteurellae are in line with the taxonomic relationships deduced by Smith and Thal (1965). The A and T types of Pasteurella haemolytica show a limited degree of nucleic acid homology, which reaches its maximum in the reaction between the RNA of the type-T strain 
1374 and the DNA of the type-A strain H58. This reaction, it will be noted, is unilateral. Even this high percentage value for the homology is well below the values exhibited in some interspecific hybridisations. Although little purpose would be served at this stage of bacterial taxonomic knowledge if different species names were to be given to the $\mathrm{A}$ and $\mathrm{T}$ types, it should be recalled that other microbial taxa enjoy the undisputed status of separate species despite their having close nucleic acid homologies. The study by Kingsbury (1967) of neisseria organisms illustrates this point, as also do as yet unpublished data obtained by McCullough and Hoyer in an investigation on the species of Brucella and presented at a Conference of Research Workers in Animal Diseases held in Chicago in 1965. We know of no comparable studies on the species of Salmonella, but would expect from the ease of transducibility between them that they would have extensive if not complete nucleic-acid homologies.

It was of interest to find such far-reaching homology between the nucleic acids of the two strains, 636 and H58, of $P$. haemolytica type A. As stated earlier, the two cultures differ in both surface and somatic antigens as well as in ecological characters. Until the $\mathrm{A}$ and $\mathrm{T}$ types were defined by Smith we considered that the serotype represented by strain H58 straddled the gap between strains like no. 636 and those like no. 1374. A considerable degree of nucleic acid incompatibility between strains 636 and H58 would not have surprised us. As it was, the two strains could not be reliably differentiated by the pattern of hybridisation between their nucleic acids.

\section{SUMMARY}

DNA-RNA hybridisation was attempted between strains of biotypes A and $\mathrm{T}$ of Pasteurella haemolytica. The results indicated that there was a low degree of genetic relationship between the representatives of the two types and suggested that the differences between the types were equivalent to those between different species in other bacterial genera. A high degree of nucleic acid homology was observed between two strains in biotype A.

This work was supported in part by USPHS General Research Support Grant no. FR05457. The kind advice of Dr R. C. Doi is gratefully acknowledged, and we should like to thank Dr Victor Burns and Mr Daniel Wong for the use of their scintillation counter.

\section{REFERENCES}

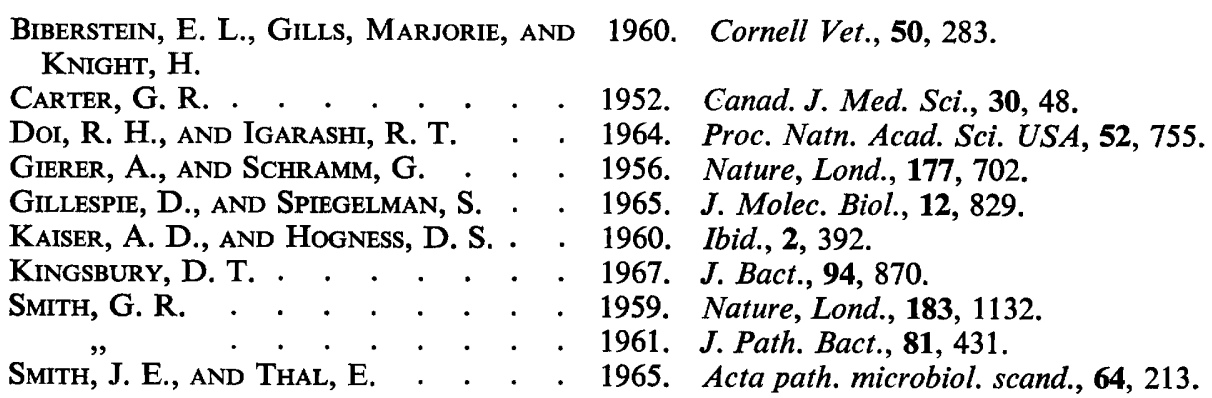

